\title{
Retraction Note: Landscape design of rainwater reuse based on ecological natural environment: Hangzhou as an example
}

\section{Rui Wang ${ }^{1}$}

Published online: 6 December 2021

C) Saudi Society for Geosciences 2021

\author{
Arabian Journal of Geosciences (2021) 14: 1877 \\ https://doi.org/10.1007/s12517-021-08127-7
}

The Editor-in-Chief and the Publisher have retracted this article because the content of this article is nonsensical. The peer review process was not carried out in accordance with the Publisher's peer review policy. The author has not responded to correspondence regarding this retraction.

The original article can be found online at https://doi.org/10.1007/ s12517-021-08127-7.

Rui Wang

wangrui361361@163.com

1 Zhejiang Tongji Vocational College of Science and Technology, Hangzhou 311231, Zhejiang, China 